\title{
Managing and Conserving Southern African Grasslands With High Endemism
}

\author{
The Maloti-Drakensberg Transfrontier Conservation and \\ Development Program
}

The Maloti-Drakensberg bioregion is the highest part of the southern African grassland biome shared by the Kingdom of Lesotho and South Africa. This bioregion is dominated by the Maloti-Drakensberg mountain range, which forms the eastern boundary between Lesotho and 3 of South Africa's provinces, namely, the Orange Free State, Kwa-Zulu/Natal, and the Eastern Cape. The combination of topographical, geological, altitudinal, and climatic variations has resulted in a dramatic landscape characterized by extraordinary natural beauty and rich biodiversity. Although the alpine and subalpine grassland vegetation types in the region are relatively well conserved in relation to other grassland types in the biome, they have been severely affected by a combination of injudicious range management regimes, the spread of alien plants, the establishment of agricultural monocultures, poor infrastructure development and maintenance, and the political engineering of human demographics. Because these grasslands form the most important component of the bioregion's ecosystems and related services such as maintenance of water catchment integrity, it is critical to derive innovative strategies that ensure sustainable solutions to the problems affecting them. The Maloti-Drakensberg Transfrontier Conservation and Development Program seeks to find natural resource and conservation management solutions by integrating biodiversity conservation and socioeconomic growth strategies.

\section{Extraordinary natural beauty and high endemism}

The geology of the region is relatively simple, with sedimentary layers of sandstone, mudstone, and shale (approximately 160-220 million years old) forming the lower slopes or "little berg" from 1400 to $1800 \mathrm{~m}$ and igneous basalts rising from this layer to well over $3000 \mathrm{~m}$, forming the ramparts, spires, cliffs, and buttresses of the main escarpment. The region is characterized by dramatic topography (Figure 1). The escarpment of the continental divide between the Indian and Atlantic Oceans drops dramatically to the east into South Africa, sloping away more gently to the west into Lesotho.

The region's function as a water catchment is important because it is one of only a few in southern Africa where long-term annual precipitation exceeds

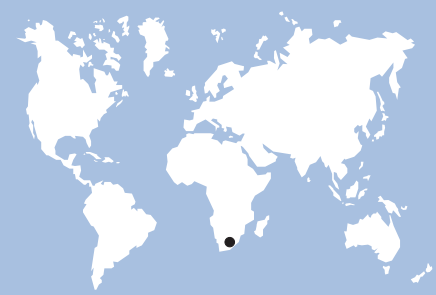

FIGURE 1 The grandeur of the

Maloti-Drakensberg Mountains: panoramic view of the Drakensberg Mountains looking north from the peak known as the Rhino to the famous Sani Pass. (Photo by Greig Stewart) 
evaporation. Biologically and hydrologically important wetlands are characteristic features of the high-altitude grasslands, helping to ensure a sustained flow of highquality water into major rivers such as the Senqu (in Lesotho), the Orange (in South Africa), and the Thukela. This water supplies a number of interbasin transfer schemes that feed Gauteng Province, the economic hub of South Africa, and its provision is currently the most obviously important ecosystem service. The listing of the entire Ukhahlamba Drakensberg Park as a Wetland of International Importance in terms of the Ramsar Convention and a pending application for the listing of the Lesotho wetlands are testimony to this important feature.

The Maloti-Drakensberg is recognized internationally as a center of endemism, with an estimated $51.5 \%$ of the plant species occurring only in this region. The World Wide Fund for Nature International has listed the Drakensberg as one of the world's 200 most important ecoregions, with 119 of the plant and animal species listed in the International Red Data Books. There are 43 southern African bird species in the region; 41 breed there and 32 are endemic. Eleven of the region's mammals are also endemic. The region is considered to be 1 of 8 major centers of reptile and amphibian diversity in southern Africa.

\section{Linking conservation and rangeland management}

The area contains a dozen formally protected areas under the management of the various participating national and provincial conservation agencies (Figure 2). The protected areas are predominantly located at the higher altitudes of this region, with a significant contrast in land use across the border in Lesotho. The adjacent land in Lesotho is communally owned and used almost solely for the grazing of livestock, namely, cattle, sheep, Angora goats (Figure 3), and horses (Basuto Pony). This is important because it accounts for this initiative being specifically referred to as a transfrontier conservation and development program rather than a transfrontier park.
It must be recognized that although the program seeks to enhance the conservation status and integrity of existing protected areas and will actively attempt to create linkages between them and expand them where possible, it will not do this at the expense of the people living in the area. Solutions have to be sustainable, and moving people from their land is not an easy option.

\section{Land use practices}

As already mentioned, agriculture is the second land use that dominates the system. The types, intensity, and success of the various agricultural practices relate directly to past and prevailing political dynamics. In South Africa, the areas that were and still are dominated by commercial farmers (mostly white) exhibit successful commercial practices that vary between livestock farming, irrigated crops, and afforestation. Because of the severe winters, with frost occurring as early as April in some parts, palatability on the natural rangelands is highly seasonal, requiring farmers to augment them with conserved feeds and cultivated pastures that are often under irrigation. Relatively high, dependable rainfall ensures the viability of dryland crops such as maize, potatoes, and soybeans. Thanks to commercial success and support from the predemocracy government, farmers in traditionally white areas were able to raise capital to develop the infrastructure necessary to support their farming activities, such as the building of impoundments and irrigation systems.

Natural grasslands are being lost to exotic timber plantations, a form of extensive dryland cropping. Although this is currently happening at a small scale, with less than $5 \%$ of the surface area transformed thus far, stock theft and market dynamics are making afforestation a more attractive alternative to private landowners. The negative impact of this land use type is well documented and entails the complete transformation and subsequent loss of grasslands and the reduction of stream flow.

Agricultural activities on tribal or community land also encompass livestock grazing and dryland cropping but at a sub- 


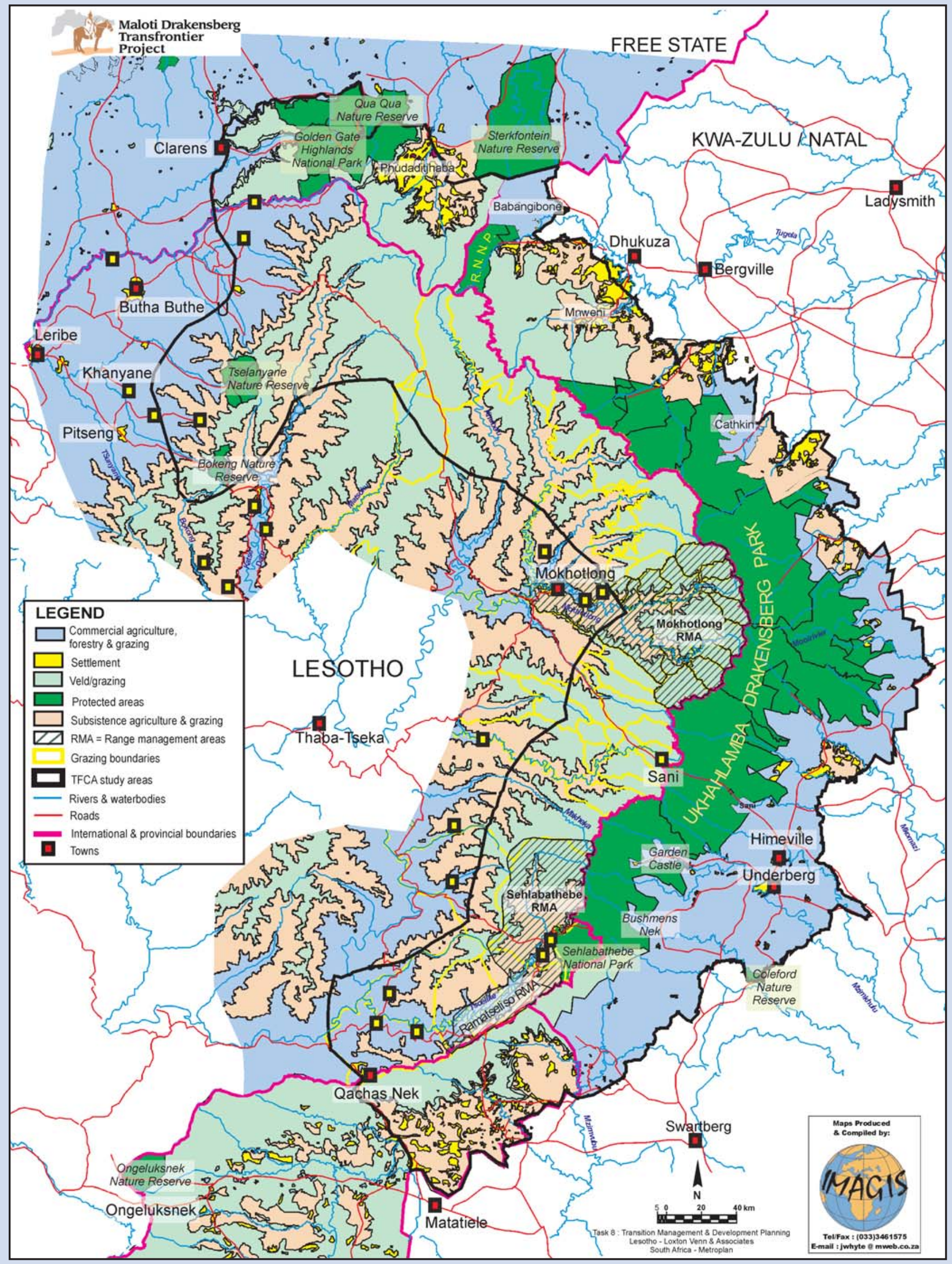

FIGURE 2 Map of the Maloti-Drakensberg Transfrontier Conservation and Development Area between Lesotho and South Africa, showing current land use. (Courtesy of Integrated Management, Analysis, and Geographic Information Services, Pietermaritzburg, South Africa) 
FIGURE 3 Herders and their goats, facing extreme conditions in the Lesotho part of the study area. (Photo by Greig Stewart) sistence level, with little or no commercial activity taking place. The exception to this is the widespread illegal production of marijuana. Economic activity in towns in the area declines after police confiscate harvested crops or spray the fields. In response to spraying, fields are prepared on extremely steep slopes in inaccessible areas that usually have a very high conservation value. It is difficult to quantify the area of montane grassland that has been lost to this activity because the statistics reflect the quantities confiscated and not the area cultivated.

Because of economic underdevelopment among the majority of the people living in tribal areas of South Africa, there is little or no improvement in water reticulation schemes and the like. Consequently, subsistence activities, although of low intensity at the family scale, have collectively led to serious degradation of grasslands, with resultant soil loss and gully erosion. Since 1994 there have been major improvements in local infrastructure including roads, water and power reticulation, schools, and clinics. However, much of this activity has been poorly coordinated, with a focus on putting infrastructure where people are located, rather than adopting a critical and holistic approach to landscape planning. Currently, local authorities are addressing these issues through the development of Integrated Development Plans (IDPs). The

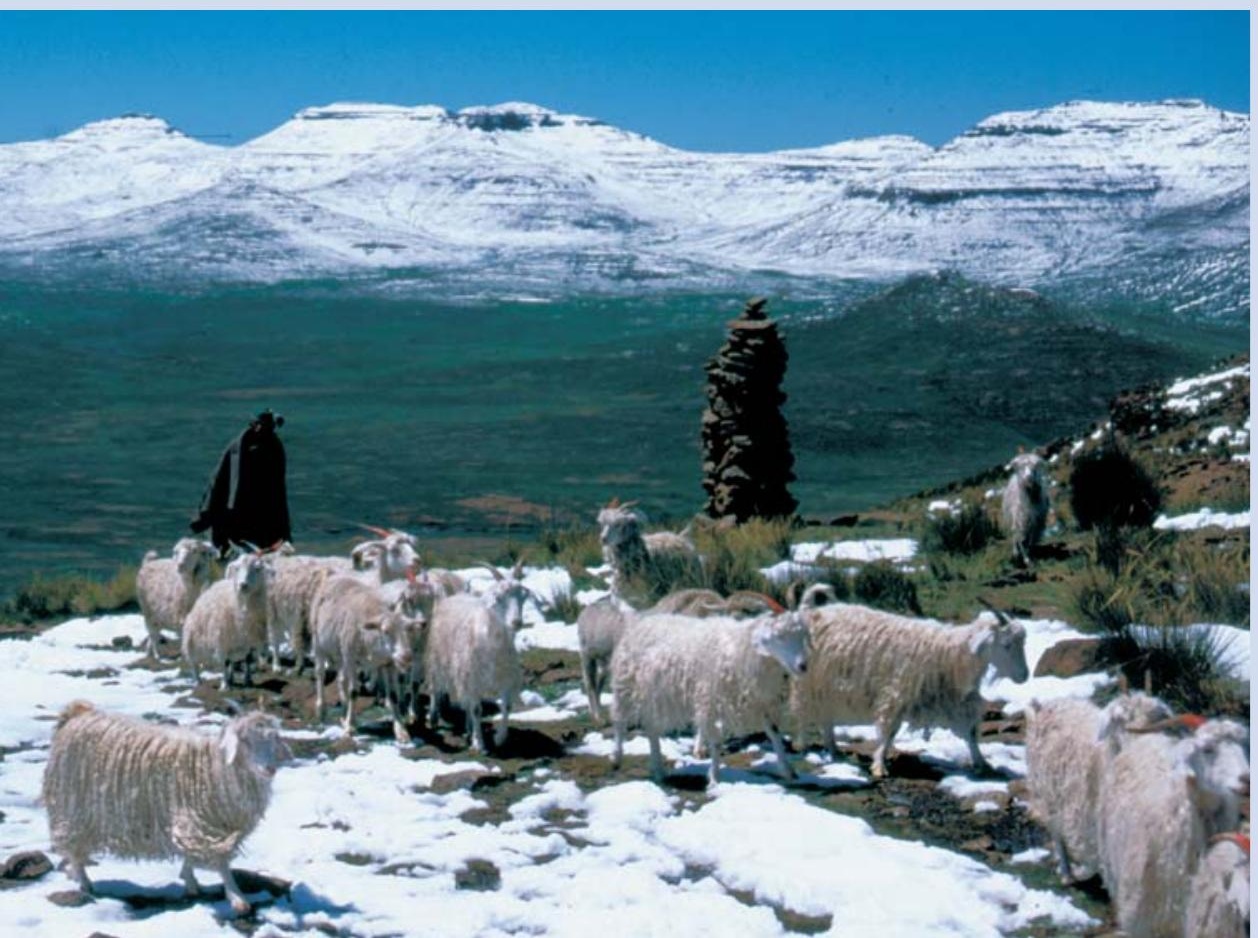

Maloti-Drakensberg Program will seek links to these IDPs, with particular reference to protection of the core conservation and ecotourism values of the region, and the facilitation of appropriate development.

The situation is very similar in Lesotho. The rangelands are a communal resource, and as the population has increased, so has the demand for livestock and the livestock population. Traditionally, large numbers of Lesotho men have worked in the South African mining industry. Because job opportunities have declined greatly in the past 20 years, thousands of returning miners have purchased livestock, thus adding to pressures on the rangelands. Estimations in the late 1980s and early 1990s were that the Lesotho rangelands were overstocked by $30-50 \%$. More recently, it has been maintained that Lesotho is the most eroded country in the world-a drastic statement that requires qualification. But there is no doubt that extensive overgrazing and soil erosion are associated with decline in water catchment integrity and loss of biodiversity.

\section{Tourism}

In addition to the conservation and agricultural land use practices discussed above, this region also has a well-established tourism industry. A study of the industry carried out in Kwa-Zulu/Natal in 2000 reached the following conclusions:

- The Drakensberg is an important tourism resource base.

- It is a "drawing card" for both local and international tourists.

- A variety of tourism markets exist, from upmarket resorts to camping facilities.

- Current supply exceeds demand.

The last finding is of significance for any socioeconomic development intervention in the area, in that effort is clearly required to increase occupancy rates. Additional tourism-related development may contribute through the initial supply of employment opportunities in the construction phase, but once development is complete, added competition could lead to further weakening of the industry. The significance of this statement in an article 
dealing with rangeland management issues is that if there are constraints within the tourism industry in terms of addressing socioeconomic growth needs, pressure on the resource base through unsustainable subsistence agriculture will simply increase, with associated impacts. Facilitation of innovative development through the provision of infrastructure and regulation of land use changes will help open up new tourism opportunities.

\section{Looking forward: conservation and development strategies}

The Maloti-Drakensberg Transfrontier Conservation and Development Program is the culmination of numerous efforts by concerned people and agencies on either side of the border to find collaborative solutions to the challenges facing people living in the area, while addressing the need to secure its conservation integrity (Figure 4). There is keen understanding that biodiversity conservation efforts will not succeed alone and that pressing socioeconomic needs must be addressed simultaneously. A multifaceted approach has been designed; it includes the following components:

- Project management and transfrontier cooperation: Strong regional coordination mechanisms are essential.

- Conservation planning: The current fragmented area and its management are brought together in a strategic conservation and development plan. The area needs to be zoned to ensure that its globally significant biodiversity is protected and properly managed, while development and various forms of use are appropriately directed.

- Protected area planning: It is essential that protected areas, as the core of the region, have planning processes in place that are always up-to-date or at least flexible enough to respond to the dynamics in their management planning environments.

- Community involvement: There is a need to ensure that communities have the capacity to participate and contribute meaningfully to this program and that the program has the capacity to recog-

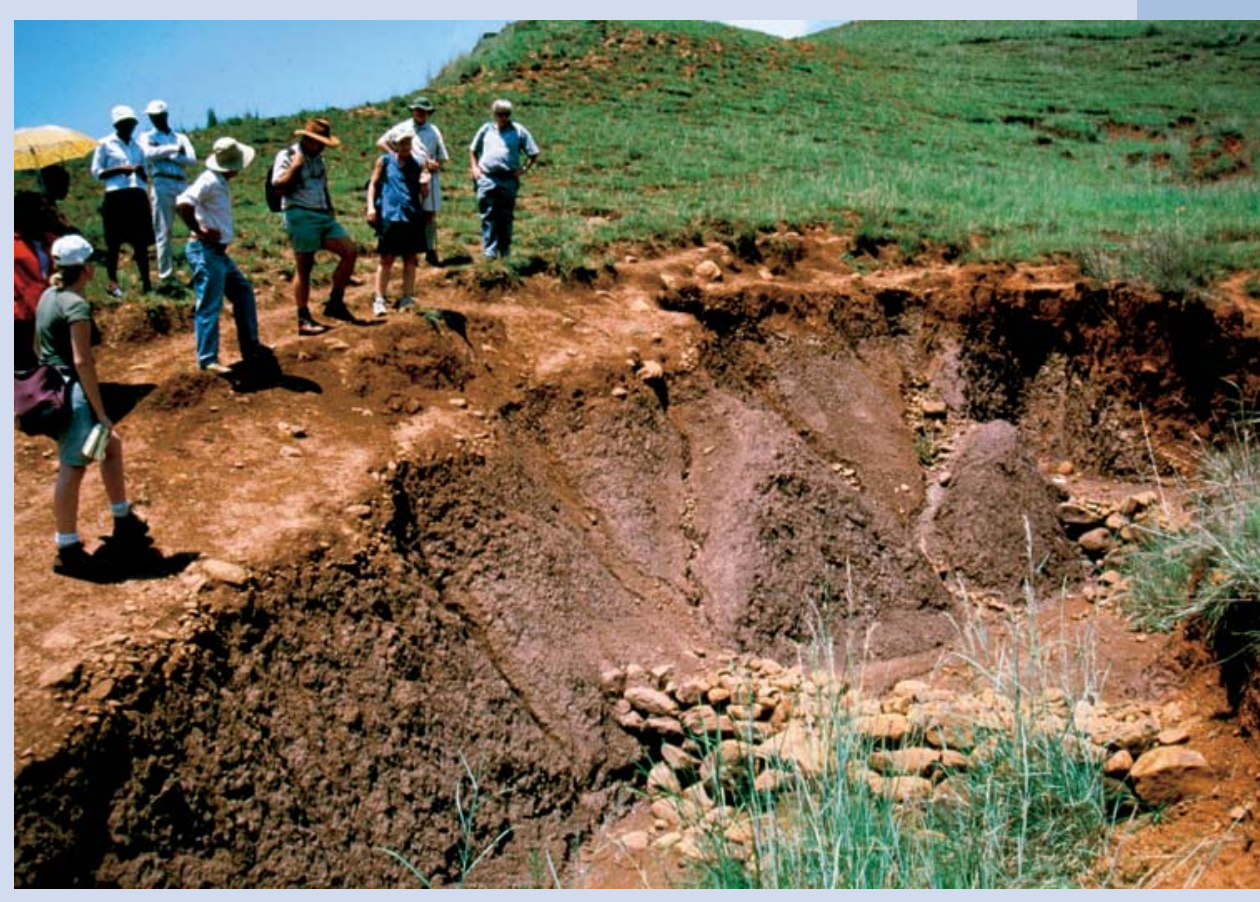

nize and integrate traditional knowledge and community needs and expectations into planning and strategy.

- Conservation management in existing protected areas: The integrity of the existing protected areas is threatened (eg, by the spread of invasive alien plants, soil erosion, unsynchronized burning regimes, poor security, encroachment of incompatible external dynamics such as grazing of livestock, poor waste management, and inadequate management of cultural resources). The program will work to build management capacity to deal with these issues so that the conservation integrity of the existing protected areas will be significantly enhanced, together with the managerial capacity to maintain the standard.

- Conservation management outside of protected areas: A host of negative dynamics threaten the conservation integrity and productivity of these areas-particularly overgrazing, injudicious burning, and the resultant soil erosion and loss of wetlands. It is hoped that appropriate management solutions (Figure 5) can be derived through collaborative initiatives to ensure the sustainable use of the natural resource base. Experience garnered by the National Range Management Area Program in Lesotho will
FIGURE 4 Gully erosion near Mnweni, in the Kwa-Zulu/Natal part of the study area. The local community has undertaken reclamation work to halt erosion. (Photo by Greig Stewart) 


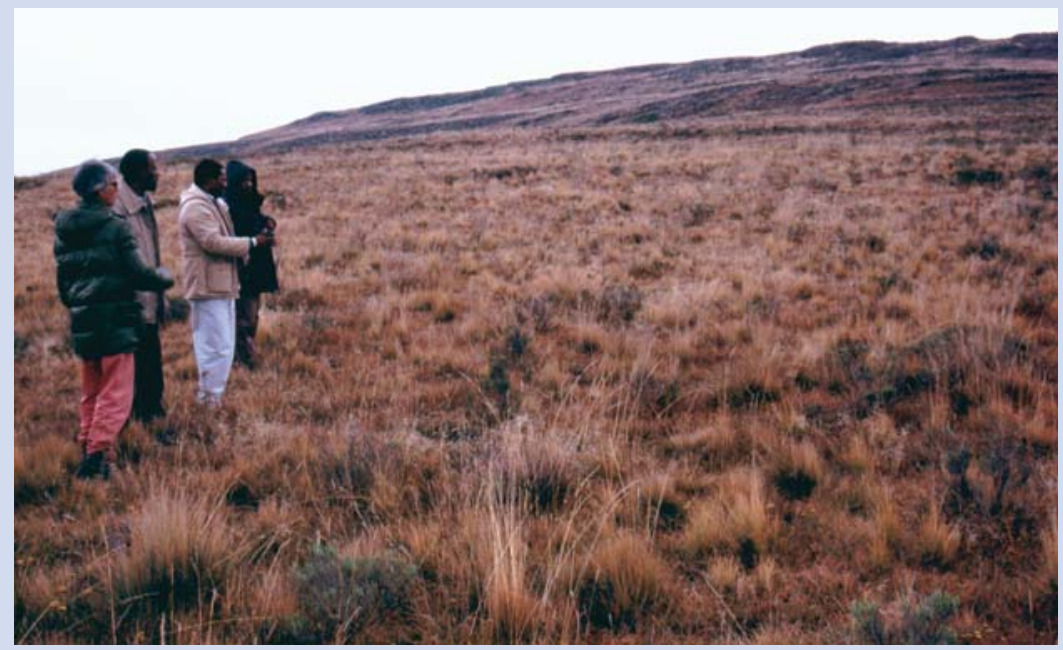

help in the development of specific strategies for grassland conservation (see Box).

- Sustainable livelihoods: The program will facilitate the identification and enhancement of entrepreneurial opportunities entrenched in the natural and cultural resource base of the study area, as well as the training of business management skills required to support and sustain these opportunities.

- Institutional development: For this program to survive beyond the time allotted for it, strong institutional capacity and linkages must be in place at the international, national, local, and community levels. This will require critical review and updating of legislation at various levels as well as the establishment, institutionalization, and maintenance of appropriate structures.

\section{Conclusion}

Irwin D, Irwin P 1992. A Field Guide to the Natal Drakensberg. Revised 2nd ed. Grahamstown, South Africa: Rhodes University.

Pierce SM, Cowling RM, Sandwith T, MacKinnon K. 2002. Mainstreaming Biodiversity in Development: Case Studies from South Africa. Washington, DC: The World Bank, Environment Department.

Town and Regional Planning Commission. 2001. A Special Case Area Plan for the Drakensberg. Main Series, Volume 90. Kwa-Zulu/Natal Town and Regional Planning Commission. Available from the author.

Van der Linde $H$, Oglethorp J, Sandwith T, Snelson D, Tessema Y. 2001. Beyond Boundaries: Transboundary Natural Resource Management in Sub-Saharan Africa. Washington, DC: Biodiversity Support Program.

Weaver LC, Sekoto MG. 1991. Community-Based Natural Resource Management in Lesotho. Internal Report of the Range Management Division of the Lesotho Ministry of Agriculture, Cooperatives and Marketing. Available from the author.

The Maloti-Drakensberg Mountains are an important bioregion because they host globally significant biodiversity, ensure the sustained provision of high-quality water to both South Africa and Lesotho, are highly attractive to both local and international tourists, and support both commercial and subsistence agriculture. Complex socioeconomic and sociopolitical dynamics significantly complicate the formulation and implementation of natural

\section{AUTHOR}

Kevan Zunckel

PO Box 13053, Cascades, Pietermaritzburg 3202, KwaZulu/Natal, South Africa. zunckelk@kznwildlife.com Kevan Zunckel is Program Coordinator for the Maloti-Drakensberg Transfrontier Conservation and Develop-
FIGURE 5 Improved rangelands in Lesotho after successful implementation of range management strategies. (Photo by Greig Stewart)

resource management strategies. In addition, the natural resource management and conservation agencies in the bioregion have serious financial limitations that significantly affect their ability to meet their responsibilities. Consequently, reliance on donor and grant funding is developing in South Africa and is prevalent in Lesotho. However, the net result is that the Basotho people have developed an aversion to external interventions. The authors of the Maloti-Drakensberg Transfrontier Conservation and Development Program have taken this into account, and those entrusted with its implementation are looking forward to building on the successes of the past while taking heed of the lessons learned from the failures.

National Range Management Area Program (established in 1982)

Goals

- To increase the productivity and income of rural livestock producers.

- To facilitate commercialization of the extensive livestock industry, while satisfying the subsistence needs of rural households.

- To initiate management of renewable natural resources in a manner that is sustainable and socially acceptable to rural Basotho.

\section{Strategies}

- Establishment of Range Management Asso ciations that will be given the responsibility and authority to achieve the above goals. ment Program. His previous experience in montane grassland conservation and development in southern Africa includes work for the Ekangala Grassland Biosphere Initiative as well as supervision of a Strategic Environmental Assessment in the high-altitude grasslands of Mpumalanga Province as the former General Manager of Research and Development in this province. 